\title{
Annual Report of the Poison Control Centre, Ain Shams University Hospitals, Cairo, Egypt, 2012
}

\author{
Heba M Halawa, Saad A Nageeb,,2, and Mahmoud Kh El Guindi²
}

\author{
${ }^{1}$ Forensic Medicine and Clinical Toxicology department \\ ${ }^{2}$ Poison Control Center \\ Faculty of Medicine, Ain Shams University, Cairo, Egypt
}

\begin{abstract}
Background: Poisoning is a growing potential threat to the Egyptian community. The Poison Control Centre Ain Shams University Hospitals (PCCA) received 19744 cases in the year 2012. The aim of this study is to portray the pattern of poisoning among cases admitted to (PCCA) in the year 2012 to evaluate the commonest poisoning causes, ways of management and outcomes during that year. Methods: Computerized data of a specially designed program comprised demographic in addition to clinical and management data of the poisoning cases received in PCCA in the year 2012. A descriptive analysis and statistics of the medical records is accomplished. Results: Overall, 19 744poison exposure cases were recorded. The largest poisoning affection was at the age group of $15-<25$ years accounting for $38.3 \%$ of total cases .Female poisoning predominate representing 55\% of total cases. Attempted suicide was obviously more common representing $49.5 \%$ of total cases. Substances most frequently involved were food poisoning, organophosphate, household products and tramadol that obviously increase yearly over the last few years. Clinical severity according to Persson et al., (1998) was mild in (84.1\%) of cases, moderate in $12.8 \%$ and severe in $3.1 \%$. Seventy eight fatalities were recorded. Management of these cases was described. Conclusions: Special attention has been drawn towards increased attempted suicide in adolescents and early adulthood, the younger age of drug users and the progressive increase of some drugs of abuse.
\end{abstract}

Keywords acute poisoning, clinical management, outcome, PCCA

\section{Introduction}

U nintentional and intentional exposures continue to be a significant cause of morbidity and mortality in Egypt. Poisoning exposure is an increasingly public concern due to the progressive flooding of chemicals, pharmaceuticals and natural toxins in the international markets. Factors enhancing this poisoning expansion are multiple and complex in any country. Poison Control Centre (PCC) is witnessing a continuously changing poisoning pattern closely reflecting the changes in industry, economy, and social configurations. The wide availability of chemicals and medications has led to increased exposure of humans to potential poisons. An unavoidable result has been an increase in the number of poisonings related fatalities (Dulger et al., 2012). Since the beginning of the twentieth century industrialization and technological advancement have resulted in an exponential growth in the number of chemicals introduced into the environment, workplace and home. These include medications, cleaning substances, pesticides, petroleum distillates, and drugs of abuse (Wax, 2006).

The information released by the poison control centre has always been a trigger for laws and regulations revision and a warning for an increasing hazard challenging the community. Despite the continuous update of information on poisons and intoxications, several problems have yet to be resolved: a) there is still insufficient awareness regarding the potential hazards of poisons, b) physicians are still not adequately trained in clinical toxicology, and c) keeping pace with the increasing amount of information has not always been 
possible due to its huge volume, limited availability and insufficient clinical exposure (Hoffman, 2007).

\section{Aim of the work}

The aim of this study is to portray the pattern of poisoning among cases admitted to the Poison Control CentreAin Shams University Hospitals (PCCA) in the year 2012 to help us to evaluate the commonest poisoning causes, ways of management and outcomes during this year.

\section{Subjects and methods}

The present study is a retrospective annual study involving all cases presented to the PCCA during the year $2012\left(1^{\text {st }}\right.$ January 2012 to $31^{\text {st }}$ December 2012$)$, taking in consideration that the centre was closed for 2 months during this period due to curfew and several hospital attacks. The total number of presented cases was 19744 cases.

Data was collected from computerized data of a specially designed program comprised demographic, clinical and management data of the poisoning cases received in the centre. The demographic and clinical management data collected throughout the study period were tabulated and statistically analysed.

\section{Results}

Age distribution revealed that the largest poisoning affection was at the age group of 15 - <25years accounting for $38.3 \%$ of total cases followed by the age group 25-40 years then age group $<7$ years (table1). The sex distribution revealed female predominance (table 2). Most of cases originated from urban area (70\%) and 30\% from rural area (Table 3).

Route of poisoning was mostly oral in $95.2 \%$ of cases. Other routes included inhalation in $2.3 \%$ of cases, bites and stings in $1.9 \%$, dermal route in $0.5 \%$, and injection in $0.06 \%$ of cases (Table 4 ).

Study of the mode of poisoning revealed attempted suicide in $49.53 \%$ of the cases (with female predominance $74.4 \%$ of suicidal cases), accidental mode of poisoning was next in frequency and accounted for $40.6 \%$ of cases followed by drugs of abuse $9.7 \%$, therapeutic error in $0.09 \%$ and criminal cause in $0.08 \%$ of cases (Table 5).

Pharmaceuticals were responsible for $56.3 \%$ of cases, non-drugs chemicals and environmental hazards represented $43.7 \%$ of cases (Table 6). The most frequently involved drugs were Central nervous system (CNS) drugs $(8.9 \%)$, analgesics $(8.1 \%)$, tramadol $(8 \%)$, and Cardiovascular (CVS) drugs (7.5\%) of the total poisoned cases (Table 7). While the highest percentage of the non-drug poisoning was related to food and fish poisoning (14.6\%), organophosphate insecticides $13 \%$, followed by household cleaning products $(10.1 \%)$ (Table8).

Poisoning severity according to Persson et al., (1998) was mild in the majority (84.1\%) of cases, (these cases are either asymptomatic or presented with mild symptoms, received medical care in the emergency department and observed for less than 6 hours). Moderately severe cases represented $12.8 \%$ of cases, (these cases are presented with moderated symptoms that need inpatient admission for $6-24 \mathrm{~h}$ ), and severe casesrepresented $3.1 \%$ of cases (these cases are presented with severe life threatening symptoms that need ICU admission) (Table 9).Period of hospitalisation was less than 6 hours for the largest number of patients $(84.1 \%)$ reflecting the mild severity of poisoning. In $11.8 \%$ of patients the period of inpatient admission was $6-24 \mathrm{~h}$, in $3.7 \%$ of the patients was from $2-<4$ days and in $0.4 \%$ it extended more than 4days (Table 10).

Decontamination procedures were accomplished on $14.9 \%$ of cases either in the form of gastric lavage, ipecac emesis or skin wash. Enhanced elimination in the form of activated charcoal was administered for $14.8 \%$ while hemodialysis was the mainstay treatment of 10 cases. Mechanical ventilation was needed in $30 \%$ of ICU cases $(0.9 \%$ of the total cases) (table11). Antidotes treatment accounted for $5.2 \%$ of cases (table 12$)$.

Death occurred in seventy eight cases $(0.4 \%$ of the total cases). The leading cause of death was organophosphate in 20 cases $(25.6 \%$ of death cases), followed by tramadol in 14 cases (18\% of death cases), carbon monoxide poisoning in 9 cases $(11.5 \%$ of death cases), and centrally acting drug in 8 cases $(10.3 \%$ of death cases). The other causes of death from different poisons are displayed in (Table 13).

Table1: Age distribution of poisoned cases received in PCC during the year 2012.

\begin{tabular}{|l|c|c|}
\hline Age (years) & No & \% \\
\hline$<7$ & 4526 & $22.9 \%$ \\
\hline $7-<15$ & 1082 & $5.5 \%$ \\
\hline $15-<25$ & 7558 & $38.3 \%$ \\
\hline $25-40$ & 4983 & $25.2 \%$ \\
\hline$>40$ & 1595 & $8.1 \%$ \\
\hline Total & 19744 & $100 \%$ \\
\hline
\end{tabular}


Table 2: Sex distribution of poisoned cases received in PCC during the year 2012.

\begin{tabular}{|l|c|c|}
\hline \multicolumn{1}{|c|}{ Sex } & No & \% \\
\hline Female & 10865 & $55.0 \%$ \\
\hline Male & 8879 & $45.0 \%$ \\
\hline Total & 19744 & $100 \%$ \\
\hline
\end{tabular}

Table 3: Residence of poisoned cases received in PCC during the year 2012.

\begin{tabular}{|l|c|c|}
\hline Region & No & \% \\
\hline Urban & 13807 & $70 \%$ \\
\hline Rural & 5937 & $30 \%$ \\
\hline Total & 19744 & $100 \%$ \\
\hline
\end{tabular}

Table 4: Routes of poisoning of poisoned cases received in PCC during the year 2012.

\begin{tabular}{|l|c|c|}
\hline \multicolumn{1}{|c|}{ Route } & No & \% \\
\hline Oral & 18804 & $95.24 \%$ \\
\hline Bite / sting & 365 & $1.9 \%$ \\
\hline Inhalation & 463 & $2.3 \%$ \\
\hline Dermal & 100 & $0.5 \%$ \\
\hline Injection & 12 & $0.06 \%$ \\
\hline Total & 19744 & $100 \%$ \\
\hline
\end{tabular}

Table 5: Mode of poisoning of poisoned cases received in PCC during the year 2012.

\begin{tabular}{|l|c|c|c|}
\hline \multicolumn{1}{|c|}{ Mode } & Male NO (\%) & Female NO (\%) & Total No (\%) \\
\hline Accidental & $4442(55.4 \%)$ & $3575(44.6 \%)$ & $8017(40.6 \%)$ \\
\hline Suicidal & $2506(25.6 \%)$ & $7274(74.4 \%)$ & $9780(49.5 \%)$ \\
\hline Drug of abuse & $1914(100 \%)$ & - & $1914(9.7 \%)$ \\
\hline Criminal & $7(44 \%)$ & $9(56 \%)$ & $16(0.08 \%)$ \\
\hline Therapeutic error & $10(59 \%)$ & $7(41 \%)$ & $17(0.09 \%)$ \\
\hline Total & $8879(45 \%)$ & $10865(55 \%)$ & $19744(100 \%)$ \\
\hline
\end{tabular}

Table 6: Type of causative agents of poisoned cases received in PCC during the year 2012.

\begin{tabular}{|l|c|c|}
\hline \multicolumn{1}{|c|}{ Type } & No & $\mathbf{\%}$ \\
\hline Drugs & 11116 & $56.3 \%$ \\
\hline Non- drug & 8628 & $43.7 \%$ \\
\hline Total & 19744 & $100 \%$ \\
\hline
\end{tabular}

Table 7: Drugs involved in poisoned cases received in PCC during the year 2012.

\begin{tabular}{|l|c|c|}
\hline \multicolumn{1}{|c|}{ Drug } & No & \% \\
\hline CNS drugs & 1754 & $8.9 \%$ \\
\hline Analgesics & 1590 & $8.1 \%$ \\
\hline Tramadol & 1581 & $8 \%$ \\
\hline Cardiovascular drugs & 1485 & $7.5 \%$ \\
\hline Cannabis & 322 & $1.6 \%$ \\
\hline Heroin & 68 & $0.3 \%$ \\
\hline Miscellaneous & 4316 & $21.9 \%$ \\
\hline Total & 11116 & $56.3 \%$ \\
\hline
\end{tabular}


Table 8: Non-drug agents involved in poisoned cases received in PCC during the year 2012.

\begin{tabular}{|l|c|c|}
\hline \multicolumn{1}{|c|}{ Type } & No & \% \\
\hline Food poisoning & 2671 & $13.5 \%$ \\
\hline Fish poisoning & 203 & $1.1 \%$ \\
\hline Organophosphorous insecticides & 2571 & $13 \%$ \\
\hline Household & 2003 & $10.1 \%$ \\
\hline Ethanol & 238 & $1.2 \%$ \\
\hline Methanol & 5 & $0.1 \%$ \\
\hline Scorpion & 199 & $1 \%$ \\
\hline Snake & 167 & $0.8 \%$ \\
\hline Carbon Monoxide & 450 & $2.3 \%$ \\
\hline Miscellaneous & 121 & $0.6 \%$ \\
\hline Total & 8628 & $(43.7 \%)$ \\
\hline
\end{tabular}

Table 9: Grading of severity of poisoned cases received in PCC during the year 2012 according to Persson et al., (1998).

\begin{tabular}{|l|c|c|}
\hline Degree of severity & No & $\mathbf{( \% )}$ \\
\hline Mild & 16602 & $84.1 \%$ \\
\hline Moderate & 2529 & $12.8 \%$ \\
\hline Severe & 613 & $3.1 \%$ \\
\hline Total & 19744 & $100 \%$ \\
\hline
\end{tabular}

Table10: Period of hospitalization of poisoned cases received in PCC during the year 2012.

\begin{tabular}{|l|c|c|}
\hline Period of hospitalization & No & $\mathbf{( \% )}$ \\
\hline$<6 \mathrm{~h}$ & 16602 & $84.1 \%$ \\
\hline $6 \mathrm{~h}-<1 \mathrm{~d}$ & 2320 & $11.8 \%$ \\
\hline $2 \mathrm{~d}-<4 \mathrm{~d}$ & 738 & $3.7 \%$ \\
\hline $4-<7 \mathrm{~d}$ & 39 & $0.2 \%$ \\
\hline$>7 \mathrm{~d}$ & 45 & $0.2 \%$ \\
\hline Total & 19744 & $100 \%$ \\
\hline
\end{tabular}

Table 11: Interventions offered to acutely poisoned cases received in PCC during the year 2012.

\begin{tabular}{|l|c|c|}
\hline Type of intervention & No & $(\mathbf{\%})$ \\
\hline Ipecac Emesis & 2497 & $(12.7 \%)$ \\
\hline Gastric lavage & 345 & $(1.7 \%)$ \\
\hline Skin wash & 100 & $(0.5 \%)$ \\
\hline Activated charcoal & 2918 & $(14.8 \%)$ \\
\hline Hemodialysis & 10 & $(0.05)$ \\
\hline Endotracheal intubation & 267 & $(1.4 \%)$ \\
\hline Mechanical Ventilation & 185 & $(0.9 \%)$ \\
\hline
\end{tabular}


Table 12: Antidote offered to acutely poisoned cases received in PCC during the year 2012.

\begin{tabular}{|l|c|c|}
\hline \multicolumn{1}{|c|}{ Antidotes } & No & $(\mathbf{( \% )}$ \\
\hline Atropine & 618 & $(3.1 \%)$ \\
\hline Obidoxime & 182 & $(0.9 \%)$ \\
\hline Bicarbonate & 55 & $(0.3 \%)$ \\
\hline Naloxone & 35 & $(0.2 \%)$ \\
\hline Dextrose 25\% & 35 & $(0.2 \%)$ \\
\hline N-acetylcysteine & 25 & $(0.1 \%)$ \\
\hline Snake anti-venoms & 23 & $(0.1 \%)$ \\
\hline Scorpion anti-venoms & 19 & $(0.1 \%)$ \\
\hline Flumazenil & 8 & $(0.04 \%)$ \\
\hline Ethanol & 4 & $(0.02 \%)$ \\
\hline Hyperbaric oxygen & 5 & $(0.03 \%)$ \\
\hline Calcium gluconate & 4 & $(0.02 \%)$ \\
\hline Glucagon & 1 & $(0.005 \%)$ \\
\hline Antibotulinum & 1 & $(0.005 \%)$ \\
\hline Dysferal & 3 & $(0.02 \%)$ \\
\hline Total & 1018 & $(5.2 \%)$ \\
\hline
\end{tabular}

Table13: Death-related offending agents in 78 acutely poisoned cases received in PCC during the year 2012.

\begin{tabular}{|l|c|c|}
\hline \multicolumn{1}{|c|}{ Agent } & No & \% of death cases \\
\hline Organophosphate & 20 & $25.6 \%$ \\
\hline Tramadol & 14 & $18 \%$ \\
\hline Carbon monoxide & 9 & $11.5 \%$ \\
\hline CNS drugs & 8 & $10.3 \%$ \\
\hline Hydrogen sulphide & 5 & $6.4 \%$ \\
\hline Opiate & 3 & $3.8 \%$ \\
\hline Methanol & 3 & $3.8 \%$ \\
\hline Kerosene & 3 & $3.8 \%$ \\
\hline Corrosive & 3 & $3.8 \%$ \\
\hline Unknown & 2 & $2.6 \%$ \\
\hline Phosphide & 2 & $2.6 \%$ \\
\hline Cardiovascular drugs & 2 & $2.6 \%$ \\
\hline Snake & 1 & $1.3 \%$ \\
\hline Paracetamol & 1 & $1.3 \%$ \\
\hline Non toxic & 2 & $2.6 \%$ \\
\hline Total & 78 & $100 \%$ \\
\hline
\end{tabular}

\section{Discussion}

The PCC of Ain Shams University is the first and largest national poison treatment centre in Egypt. Another important issue in the field of poisoning is that recommendations and guidelines for optimum treatment are currently based on observational data.The annual report of the year 2012 describes a total number of 19744 poisoned patients received and managed in the centre.

The results of the collected data revealed that $63.5 \%$ of poison exposures were at the age 15-40 years while $22.9 \%$ of poison exposures were children under 7 years. The lowest incidence of poisoning was at age group $7-<15$ years $(5.5 \%)$ and over 40 years $(8.1 \%)$ (Table1). The high incidence of poisoning in the early adulthood and middle age deserve particular attention. This poisoning prone age group is subject to tremendous emotional and economic challenges in Egypt. Comparison to other countries whether Arabic or western revealed that the greater majority of poisoning cases usually lie in the age group below 6 years of age. The 2011 annual report of the American Association of Poison Control Centres revealed that children under age of 6representup to $49 \%$ of all poison exposures (Bronstein et al., 2012). The Saudi Arabia Report of acute chemical poisoning during the first six months of year 2004 revealed that the highest proportion of acute poisoning was observed among children $\leq 5$ years of age (Moazzam et al., 2004). These observations strongly point to political and economic challenges affecting principally the most vulnerable and conscious age group in Egypt. Other factors include interlinked emotional, social, and financial stresses.

The residence data revealed that most of cases originated from urban areas (70\%). This is attributed to the proximity of these areas to the PCCA and not to the 
higher magnitude of the poisoning health problem. (table3).

The data result revealed that the oral route was the most common route of poisoning (95.2\%) (table4) (Andiran and Sarikayalar, 2004) found that the oral route was the most common route of poisoning in a retrospective study showing the pattern of acute poisonings in childhood in Ankara, Turkey during 20 years. Also Alvin et al., (2011) reported that the oral route was the most common route of poisoning representing $79.5 \%$ of poisoned cases in the United States of America.

It is evident from this study that attempted suicide $(49.5 \%)$ exceeded accidental $(40.6 \%)$ poisoning exposure (table 5). Most of attempted suicide was induced by females $(74.4 \%)$. This incidence of suicide is higher $(69 \%)$ in the age group $15-25$ years. This agrees with Dulger et al., (2012) who reported that $2 / 3$ of cases were women and young female patients between the ages of 16 and 25 years had a higher rate of intentional poisoning inTurkey. This phenomenon may be due to accelerated social turmoil particularly in rural areas of the country and contributes substantially to the suicide burden in female gender.

A more alarming figure is the attempted suicide among the pubertal development age (10 $-<15$ years), the large majority of which (77\%) are girls. These results agree with Goksu et al., (2002) who studied the characteristics of acute adult poisoning in Gaziantep, Turkey and also El Masry and Tawfik (2013), who found that most attempted suicide poisoning cases were among teenagers and young adults, females significantly outnumber males and drugs were the commonly used in intentional poisoning in Cairo, Egypt in 2011.

In contrast, the 2011 annual report of the American Association of PCCs found that only $15.8 \%$ of poisoning was intentional Bronstein et al., (2012). Despite the strong religious morals in Islam and Christianity that ban self-destruction and deliberate selfkilling, yet young adults seem not immune to the attempted suicide.

Children of preschool age (<7years) particularly male, were subjected to poisoning accidents in $(55 \%)$, this can be attributed to the particular behaviour of that age group as curiosity, oral identification, discrimination inability and taste and smell immaturity. These results were similar to those of Andiran and Sarikayalar 2004 who found that accidental poisoning was commonest amongst children and remains a significant problem for this age group.

The collected data in the present study revealed that $56.3 \%$ were due to drug poisoning in 2012 compared to $46.7 \%$ of the cases in 2011 , this means an increase in the drug poisoning. While non drug poisoning in 2012 account for $43.7 \%$ of cases.

The top 5 substance classes frequently involved in all poison exposures, in the present study, were food poisoning $(14.6 \%)$, organophosphate $(13 \%)$, household $(10 \%)$ CNS drugs and $(8.9 \%)$ tramadol $(8 \%)$. In the
United States, The top 5 substance classes most frequently involved in all human exposures were analgesics (11.7\%), cosmetics/personal care products $(8.0 \%)$, household cleaning substances $(7.0 \%)$, sedatives/hypnotics/antipsychotics (6.1\%), and foreign bodies/toys/miscellaneous (4.1\%) (Bronstein et al., 2012). Affirming different Egyptian profile of poisoning compared to the American profile of poisoning. Food poisoning in Egypt could be attributed to improper storage of food and increasing use of pre-prepared dishes which are not always stored or reheated properly. In addition to food contamination with various pathogens like bacteria and viruses. Although the percentage of food poisoning was relatively high $(14 \%)$, yet it does not reflect the real magnitude of the problem of food poisoning in Egypt, apart from scombroid ,ciguatera, and botulism, cases are not referred to PCC. In the present study, the vast majority of the food poisoning cases were clinically of toxigenic type.

In Turkey, substances frequently involved in poison exposures include central nervous system drugs $(21.8 \%)$, carbamates $(17.1 \%)$, analgesics $(10.3 \%)$ and organophosphorus components $(10 \%)$ were most used agents among intoxicated patients (Dulger et al., 2012).

The majority of cases in the present study were managed in the emergency rooms and released for home treatment after a period of observation of 6 to 24 hours.

An alarming figure has been the progressive rise of tramadol overdose amounting to 1581 in the year 2012and 1595 cases in 2011 (El Masry and Tawfik, 2013) compared to 386 cases in 2009 and 760 cases in 2010. National Poison Data System (NPDS) Annual reports (1983-2011) indicate that all analgesic exposures including opioids and sedatives are increasing year after year. These data and daily observations of the magnitude of the problem enabled the PCC Ain Shams to declare new recommendations concerning drug of abuse screening list and issue several warnings in media that were given much concern by the health and drugs of abuse authorities.

Exposure to animal stings and bites were of relatively low percentage in the present study $(1.8 \%)$. Almost a third of snake bite originated from Guiza, Bahareya oasis (all viperidae type), a third from close governorates (mainly elapidae type) and the last third from greater Cairo. Scorpion stings most serious clinical presentation was in the children groups. They mainly originated from suburban, rural areas and growing new cities that invade the territories of scorpions and snakes. Despite the severity of animal exposure, the outcome was relatively satisfactory with a mortality of $0.3 \%$. This was attributed to the availability of anti-venom and strict guidelines concerning these exposures emergencies in PCCA and non-aggressive species especially in scorpion.

A smaller mortality is declared in the 2010 annual report of the American Association of PCC $(0.027 \%)$ amounting to 17 cases while it was much higher in Mexico; 1000 deaths from scorpion stings occurring per year (Bush and Charles, 2003). 
The recorded mortality rate in our series was considered comparatively low ( $0.4 \%$ of the total cases). Shadnia, (2007) found that mortality rate in Tehran (2003) was $1.3 \%$ in the study conducted in Iran. Another report from Saudi Arabia, (1999-2003) revealed a mortality rate of $2.2 \%$ (Moazzam et al., 2004). In contrast, the (2011) annual report of the American Association of PCCs revealed that out of 2,334,004cases, they had 2,765 deaths (0.118\%) (Bronstein et al., 2012). However, this report included non-attending, trivial therapeutic accidents and information-seeking cases reported through telephone calls and not only symptomatizing referred poisoning cases, making the comparison unacceptable.

The large percentage of organophosphate poisoning, the relatively high severity and necessity for ICU treatment, the relatively high frequency of mechanical ventilation and the large number of fatalities, make the organophosphate problem of particular importance to the health care system, and invite for more rigid regulations concerning its misuse. As stated by Kanchan and Menezes (2008), poisoning with pesticides, especially those containing organophosphorus, has been associated with increased risk of mortality.

Decontamination procedures and activated charcoal were the most frequent procedures undertaken for poisoning cases. Antidotes followed in frequency of use. The most frequently used antidote was atropine and obidoxime reflecting the large number of received organophosphate poisoning cases.

Mechanical ventilation was a common tool in ICU admitted serious cases $30 \%$ of which were due to organophosphrous poisoning and $17.3 \%$ due to tramadol overdose reflecting the severity grade of these types of poisoning. The cost of management of organophosphate and tramadol, as evident from the above figures, are evaluated as great and incapacitating resources and budget of health care service for these specific intoxications. Compared to total number of patients in PCC on 2005 (Gamalludin et al., 2006), a substantial decrease of the total annual number was evident on 2012 , essentially due to the curfew regulations imposed by the armed forces for several months on different occasions after the 2011, January revolution. A significant decrease of organophosphate intoxications from $17 \%$ on 2005 to $13 \%$ on 2012 reflects the efforts triggered by PCC Ain Shams University, Media and Ministry Of Health to restrict the widespread use of these chemicals. On the other hand a significant rise of drug overdose was noted mainly due to the progressive dissemination of tramadol. Another impressing finding is the decrease in methanol poisoning presented cases and mortality rate due to the state's tighter control against alcoholic beverages adulteration.

\section{Conclusions}

These data support the continued value of poison center expertise and need for specialized medical toxicology information to manage the more severe exposures. Unintentional and intentional exposures continue to be a significant cause of morbidity and mortality in Egypt. The continuing mission of PCCA is to provide medical services for all types of exposures, medical education programs, public health event identification, and situational awareness tracking.

\section{Acknowledgment}

Thanks for the valuable help of Dr. Hany M. Tawfik, Fellow of Clinical Toxicology, Poison Control Center, Ain Shams University Hospitals in providing us with data and preparation of statistics of this manuscript .His effort is gratefully acknowledged.

\section{References}

Alvin C, Daniel A, Louis R et al., (2011): 2010 Annual Report of the American Association of Poison Control Centers' National Poison Data System (NPDS): 28th Annual Report. Clinical Toxicology, 49, 910-941

Andiran N and Sarikayalar F (2004): Pattern of acute poisonings in childhood in Ankara, what has changed in 20 years? Turkish Journal of Pediatrics, 46(2):147-52.

Bronstein AC, Spyker DA, Cantilena LR et al., (2012):2011 Annual Report of the American Association of Poison Control Centers' National Poison Data System (NPDS): 29th Annual Report, Clinical Toxicology, 50, 911-1164

Bush S and Charles G (2003): Scorpion envenomations. eMedicine Available online at: http://www.emedicine.com/emerg/topic524.htm

Dulger AC, Karadas S, Gonullu H et al., (2012) Analyses of Etiologic and Sociodemografic Properties of the Intoxicated Cases in Van City and its Environs. J Clinic Toxicol 2:119. doi:10.4172/2161-0495.1000119

El Masry M and Tawfik H (2013):2011 Annual Report of the Poison Control Centre of Ain Shams University Hospital, Cairo, Egypt .Ain Shams J Forensic Med ClinToxicol, January (20):10-17

Gamalludin H, EL Seddawy A, Sakr M et al., (2006): Evaluation of cases of acute poisoning received at the poison control center of Ain Shams Universiy Hospitals during the year 2005. Ain Shams J. Forensic Med. Clin. Toxicol.,Vol. VI, Jan.

Goksu S Yildirim C, Kocoglu H et al., (2002): Characteristics of acute adult poisoning in Gaziantep, Turkey. J Toxicol Clin Toxicol., 40(7):833-7.

Hoffman R (2007): Understanding the limitations of retrospective analyses of poison center data. Clin Toxicol; 45(8):943-5. 
Kanchan T, Menezes RG (2008): Suicidal poisoning in Southern India: Gender differences. J Forensic Leg Med 15: 7-14.

Moazzam M, Al-Saigul A, Naguib M et al., (2004): Pattern of acute poisoning in Al- Qassim region: a surveillance report from Saudi Arabia, 19992003, Eastern Mediterranean Health Journal, Vol. 15 , No. 4

National Poison Data System: Annual reports 19832011 [Internet]. 1. Alexandria (VA): American Association of Poison Control Centers; Available
http://www.aapcc.org/dnn/NPDSPoisonData/An nu- alReports/tabid/125/Default.aspx.

Persson H, Sjöberg G, Haines J et al., (1998): Poisoning severity score. Grading of acute poisoning. J Toxicol Clin Toxicol; 36(3):205.

Shadnia S (2007): Pattern of acute poisoning in TehranIran in 2003. Human and experimental toxicology, 26(9):753-6.

Wax P (2006): Historical principles and perspectives. In: Flomenbaum NE, Goldfrank LR, Hoffman RS, Howland MA, Lewin NA, Nelson LS,eds. Goldfrank's Toxicologic Emergencies. 8th edn. New York: McGraw-Hill,:1-17.

الملخص العربي

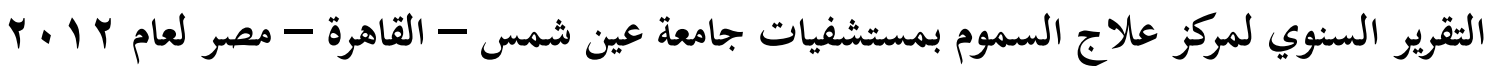
هبه محمد حلاوة و سعد أحمد نجيب '، و محمود خيرث الجندي

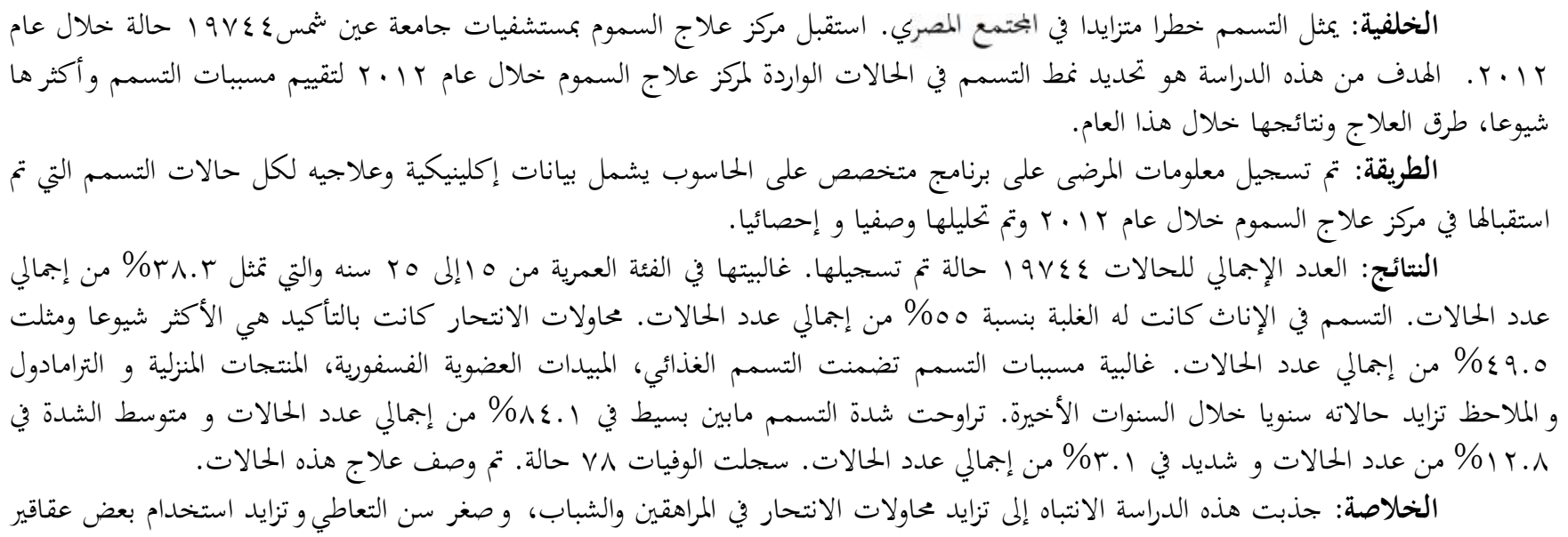

